filled with an artificial steam-fog, by means of a pipe brought from the boiler of the engine-house, and the ro8-jet Wigham gas-burner, and an electric arc fed by one machine, were pitted against each other, and the distances from which the lights could be seen determined. In all cases the electric arc became visible before the gas flame, as the observers walked up the shed towards the lights, confirming the other eye-observations which have been already mentioned.

The experiments showed also that the electric light suffered a greater proportional loss than either of the two other illuminants when passing through fog or haze, but that, owing to its far greater initial intensity, it nevertheless exceeded the other lights in its penetrating power.

The Committee add to their Report some account of the cost of the three illuminants, from which it appears that there is but little difference in the first cost of the electric and gas systems, the latter being slightly the more costly; but, on the other hand, the annual cost of the gas is estimated at rather less than that of the electricity. The cost of the mineral-oil apparatus is estimated, both for its installation and for its annual maintenance, at about two-thirds that of either gas or electricity.

The general conclusions arrived at by the Committee - conclusions which seem fully borne out by the evidence set forth in the Report-are, that the "electric light, as exhibited in the experimental tower at South Foreland, has proved to be the most powerful light under all conditions of weather, and to have the greatest penetrative power in fog ;" that for all practical purposes the gas and oil were equal; and "that for the ordinary necessities of lighthouse illumination, mineral oil is the most suitable and economical illuminant, and that for salient headlands, important landfalls, and places where a very powerful light is required, electricity offers the greatest advantages."

\section{GEOGRAPHICAL EDUCATION}

THE Council of the Royal Geographical Society have been making a determined effort during the past eighteen months to improve the position of geography in the education of this country, with special reference to the higher schools and universities. They have collected information as to the position of the subject and the methods used in teaching it in the schools and universities of the leading Continental countries as well as in England, and published the results in the form of a Report, which has attracted considerable attention, and is likely to lead to useful results. In connection with this inquiry the Society has arranged an Exhibition of Appliances in use in Geographical Education at the rooms, 53, Great Marlborough Street, which, since it was opened in the beginning of December, has attracted many visitors of the class for whose special benefit it was intended. Already there are signs that this Exhibition will do real good in at least leading to the multiplication and improvement of the meagre appliances in use in English schools. Nothing could show more strikingly the marked difference in the variety and quality of these appliances in use in English and in Continental schools.

The catalogue of the Exhibition covers 8o large octavo pages. It is arranged in eight divisions-wall-maps, globes, telluria, planetaria, \&c., models and relief-maps, geographical and ethnological pictures, atlases, textbooks, miscellaneous. Upwards of 200 wall-maps are shown, while about Ioo more have not been hung for want of space. All the leading types of this kind of work are represented on the walls. They are arranged geographically - maps of the world, of Europe, and parts of Europe, and so on. The object aimed at in hanging the maps has been to bring side by side those of the same region by different publishers and in use in different countries, so that visitors may compare the results for themselves. Some of the English work thus shown is certainly good-accurate, carefully executed, and fairly well adapted for its purpose, especially the maps of Stanford and Keith Johnston. The Exhibition, it should be remembered, is purely educational, and therefore the finest cartographical work of our best publishers and our Ordnance Survey must not be looked for; some of this work will compare favourably with the best work of other countries. As a whole, it must be admitted, that English school-maps are far behind those of the leading Continental countries, notably Germany, Austria, Switzerland, and even Italy. We do not seem to be guided by any definite principles in the construction of such maps; our teachers, as a rule, have never seen good school-maps, and the best English cartographers seem to think such work beneath them. We in England seem to cherish the pernicious idea that a school-map should be something quite different in kind from an ordinary map of the best class. In the Continental countries mentioned above, on the other hand, it is recognised that in the case of young people, even more than with men and women, only the very best work should be used, for first impressions are everything. In elementary wall-maps, of course, the minute details of the finest hill-shading and other features would be out of place, but the style and method of the work should be the same, only more generalised. For example, in Austrian schools, maps produced by photography from reliefs are absolutely forbidden on account of the exaggerated impression which they convey. The riliefs are almost necessarily exaggerated in such cases, and the light thrown on them from a particular direction to give picturesque effect; the result as a rule being a misrepresentation of the real configuration of the ground. Maps which attempt to indicate physical features by the use of variety of colour are but little used on the Continent. They do not appeal at all to the eye or help the imagination of the child, and are of no use in helping him to read maps executed in the usual way, which are the maps he must deal with when he grows up to be a man. The use of colour for special features is certainly useful, but then only in advanced classes. For the younger classes in Continental schools one does find it, but almost invariably conjoined with graphic mountain-shading. In the best maps, moreover, when the method is used, often only one, generally not more than two, colours are introduced : green for the lowest levels, tints of brown for the higher levels. In Kiepert's maps, brown alone, in deepening tints according to altitude, is used, just as blue is used after a similar fashion to indicate the varying depths of the sea. And this reminds us of the common practice in the best Continental schools, of always having two maps of the same region for teaching-purposes-one physical and the other political. On the former, always without names and political indications, the physical features are everything, and are boldly brought out; in the latter the physical features are still clear and prominent, but are accompanied by what are known as "political" features. In England one map has usually to serve not only for all grades of classes, but for both physical and political teaching: and as in our best school-maps the physical features are faint and obscured by the glaring colours used for political divisions, they are almost hidden when covered with names and other details.

In the matter of outward appearance, even, our schoolmaps leave room for great improvement. They, as a whole, cannot be eompared as to taste and style with the best Continental maps. The finest of these are either not coloured at all, or the colours are put on faintly and delicately to show political divisions; often only boundary lines are coloured, so that the physical features, which have so much to do with political development, are well shown. The taste of our teachers and map-makers in this matter requires radical reformation; the more glaring and vivid the colouring of wall-maps, the more 
popular they seem to be. They are enough to ruin the taste of pupils. As examples of what school-maps should be, those of the district of Graz, of the Canton of Zürich, of Switzerland, by Ziegler; of the Alpine countries, by von Haardt, and the same region by Randegger, may be taken as examples in various grades, from the elementary stage upwards. Only the best work should be placed before the pupil from the beginning. There is certainly one good English specimen,- - a map of the district around Bradford, by a Bradford teacher, for local geography. The scale is two inches to a mile; there is no overcrowding, and the physical features are bold, careful, accurate, and tasteful, after the best manner of hill-shading. These ought to be the characteristics of all school-maps, which ought to be a picture that the eye of the pupil can at once understand. The elementary principles of hillshading are easily learned-a few hours' teaching would do ; without it, how can the pupil be expected to read his map? It is almost better to have no names on elementary maps ; the children should be taught to look for things, not words; the teacher ought to be able to give all the names needed.

Of course, school-maps, especially for the elementary stages, should not be crowded with names and symbols, while at the same time they should be of a character that will lead up to the understanding of the best staff-maps. It is evident from the detailed and beautiful maps from Germany, Austria, and Switzerland, that geography is carried to a much higher stage in these countries than in England. Our maps seem mainly intended to answer the common English conception of geography, that of mere memory-work; the maps without names are "testmaps" to test the memory of the pupils, not physical maps, on which no names should be. Now that local geography is made the starting-point in elementary schools, we want a thoroughly good series of large county maps, with few names, but with the physical features, not in too great detail, but executed with as much care and precision as on a staff map. Local maps ought to be done by teachers themselves, as in the case of the Bradford map referred to. There are several exhibits by London Board-school teachers, creditable to their zeal and industry, but indicative of their want of enlightenment, more than of anything else.

() ne of the best means to teach the pupii to understand a map is to train him to draw maps for himself, either from a model, or, better still, from nature. This is done, we are glad to say, in several schools in this country, notably in Gordon's College, Aberdeen ; several specimens of the work thus done in the latter school are shown in the Exhibition. The map must always be the mainstay both of the geographer, of the teacher, and of the pupil, and therefore every means should be taken to train the eye and the understanding to read it as if it were a book. If this Exhibition enlightens our teachers as to the value and characteristics of really good maps, it will have accomplished much.

One of the most striking features of the Exhibition is the number of reliefs of various kinds, from the large model down to the relief-atlas. The finest relief is without doubt that of the Monte Rosa group from Zuirich. Here the vertical and horizontal scales are the same; the region embraced is comparatively small, and the scale large-I : I50,000. The relief itself is by Prof. Imfeld, an eminent Swiss engineer, while the colouring, according to nature, is, we believe, by Prof. Heim, the geologist. For teaching-purposes, for physical geography, its value is great; unfortunately its price is a bar to its general use. The reliefs of a glacier and of a volcanic island are, however, cheap enough, and should be in every school. The model, by Mr. Jordan, showing the contours of the ocean bed around our shores, is also most instructive, though the exaggeration is great -28 times. It has been constructed for the Science and Art Department. Of re- lief-maps the finest are no doubt the three sections of the Central and Eastern Alps, by Col. Cherubini, in which the vertical scale is only exaggerated twice that of the horizontal. Mdlle. Kleinhans's relief-maps of Europe and France are also fine specimens of such work. There are also German, Italian, and English relief-maps of small size, in which the vertical scale is enormously exaggerated, and which therefore, if used at all, must be used with great caution. Good reliefs are in themselves of great service in giving the pupils a vivid notion of the appearance of a region; but one of their chief uses, in our estimation, is in enabling the pupil to understand the meaning of a map. Therefore besides every relief there ought to be a map of the same region, the one being used to interpret the other. There are several so-called ideal reliefs in the collection, some of them by English Board-school teachers, in which every salient feature on the earth's surface is brought together within an area of a few inches. Such productions ought to be discouraged. Much better to make reliefs of real landscapes, say of the Isle of Wight, or of a limited area around a school; such, for example, as that of the region around Rochester or Kent, by a master in one of the schools there.

One of the most novel features in the Exhibition is the collection of geographical pictures. There are several series of them, the finest, no doubt, being that published by Hölzel, of Vienna, which, in about thirty wall-pictures, shows some of the most characteristic and typical landscapes in various parts of the world. Such pictures add greatly to the living interest, as well as to the instruction, of a lesson in geography. They must above all things be accurate, and therefore large photographs are to be preferred as models to pictures from a purely artistic standpoint. Indeed, photographs themselves, on a large scale, make excellent pictures for geographical purposes, such as those of the Yosemite Valley in the Exhibition, or the well-known photographs of the Alps by Mr. Donkin. Equally serviceable is the series of twelve typical life-size heads of races, edited by Prof. Kirchhoff, of Halle, and sold at a very cheap rate. There are also several pictures of groups of peoples in their native surroundings, some of which are very good.

The Exhibition also contains a considerable collection of globes, including slate globes of various sizes, which we think can be made of great service in the hands of a good teacher. The telluria are mostly of the well-known kind-complicated, and easily put out of order. The simpler such apparatus are, the better; children are apt to contract misleading and erroneous ideas from such things-ideas difficult to eradicate. One of the simplest is exhibited by Stanford: a glass globe with a candle for the sun, with only the earth and moon at the end of the arm. Some means should always be taken to counteract the misleading impressions as to scale conveyed by such instruments; and for this purpose an idea has been borrowed from the arrangement in the Jermyn Street Museum, showing the relative sizes and distances of the sun and planets. A yellow disk, about 6 inches in diameter, is fixed on the wall of one of the rooms, to represent the sun; and 56 feet away are two pellets of wax, $\mathrm{I} \frac{1}{2}$ inch apart-one, $\mathrm{I} / 20$ of an inch in diameter, to represent the earth; and the other, $1 / 60$ of an inch, to represent the moon. The whole arrangement is intended to show what would be the relative sizes of sun, earth, and moon, if these were reduced to a scale commensurate with a distance of 56 feet.

Another interesting exhibit is a section of the contrivance devised by Prof. G. H. Darwin, on which he read a paper to the Royal Society some years ago, intended to give a truer representation of the globe than an ordinary projection. It consists of a figure formed of twenty hexagons and twelve pentagons, the projection on which is but very slightly distorted. Of much historical and antiquarian interest are the two large Mollineux 
globes from the library of the Inner Temple, made in the time of Queen Elizabeth.

There are about 200 atlases shown, like the wall-maps, from various countries-England, Germany, France, Austria, Belgium, Holland, Italy, Switzerland, Denmark, Sweden. Even more than in the wall-maps does the superiority of Continental work to English work come out in these publications. Many of these cheap foreign schoolatlases contain some of the finest cartographical work: such as Wettstein's atlas, published in Zürich for about half-a-crown, with about thirty maps of perfect finish. In this, as in some other foreign atlases, are one or two sheets intended to give the pupil an elementary idea of the principal symbols used in cartography--notably of hill-shading. With such a knowledge the pupil will see far more in a really good map than otherwise he could possibly see. Accuracy, beauty, and adaptability to their special purposes are far more frequent characteristics of Continental school-atlases and wall-maps than of English.

of text-books there are some two or three hundred from all the countries already named, including a few from America. The vice of English text-books is the prominence given to mere memory-work, and the absence of any attempt to show the relations between physical and political geography. Of physical geographies and physiographies we have a few that are not surpassed by those of any country. It is the general text-book that is put together with so little skill and knowledge. In this departmen: foreign countries show far more unsatisfactory work than in the case of maps. Some of the best Continental text-books, especially German, are small, such as that of Kirchhoff, used in all classes of German schools, and in which mere memory-work is reduced to a minimum. In Germany, and indeed in most of the Continental countries represented, the teacher is of far more importance than the text-book, and is to a large extent independent of it ; in England everything must be put into the text-book, for few of our teachers know anything of the subject. It is a mistake altogether to write text-books for the youngest classes, those in which elementary notions and local geography are taught; these should depend entirely on the living voice of the teacher, with black-board, compass, simple reliefs, and pictures.

Such are a few of the exhibits brought together in this very useful Exhibition; there can be no doubt that the many teachers who have visited it will have learned a few useful lessons; we hope, for one thing, they will be more exacting as to the character of the maps and other appliances supplied by publishers.

A series of lectures has been arranged in connection with the Exhibition, which so far have been well attended, and been followed by useful discussions. In December two lectures were given, one on the aims and methods of geographical education, the other on appliances. Last Tuesday Mr. Bryce lectured on the historical bearings of geographical education, and next Tuesday Prof. Moseley lectures on its scientific bearings, with Sir Joseph Hooker in the chair. On Saturday next a Conference will be held, in which the whole subject of the position of geographical education will be discussed, with special reference to its place in examinations; Sir Beauchamp Walker, ex-Director of Military Education, will preside at the Conference.

\section{HUNTER'S HOUSE}

THE three subjoined drawings are very faithful delineations of some of the portions of John Hunter's house and grounds, at Earl's Court, to which I drew attention in NATURE for Jan. 7. The first drawing supplies the view of the house looking into the meadow, in which view the house is, I believe, nearly the same as it was when Hunter lived in it. The second sketch is that of the Lions' House, or den, situated at the end of the
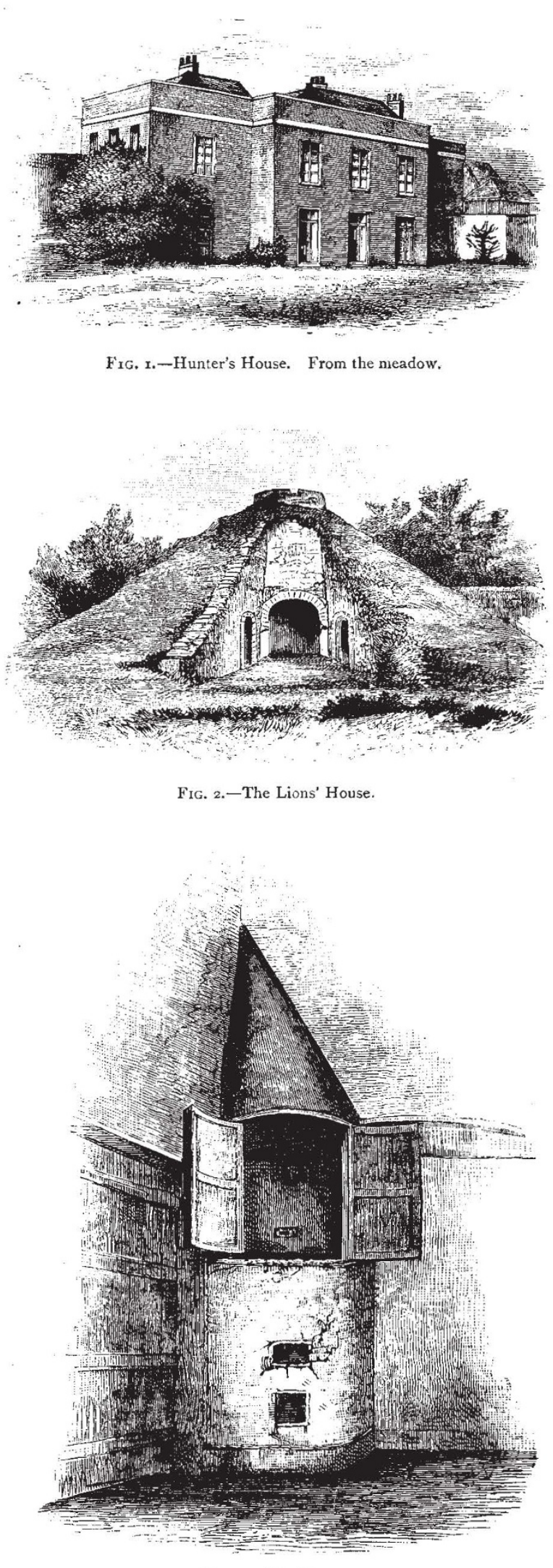

Fig. 3.-The Copper. 